\title{
Una reliquia de San Juan de la Cruz custodiada en el Convento carmelitano de San José (Medi- na del Campo). Milagro transformado en arte
}

\author{
Ana Cristina VAlero Collantes \\ Universidad de Valladolid
}

RESUMEN. En este artículo nos acercamos a la figura de San Juan de la Cruz, presencia relevante en la mística española así como reformador del Carmelo, a través del milagro acontecido en el convento carmelita de San José de Medina del Campo con una de sus reliquias. Hecho que derivó en una importante variación iconográfica, poco conocida, y que sin embargo, dio lugar a numerosas y destacadas representaciones artísticas (pinturas, grabados...) no sólo en el ámbito local, sino también nacional e incluso internacional.

Palabras clave: San Juan de la Cruz, Orden del Carmen, miracle, Vigil de Quiñones, Diego Valentín Díaz.

ABSTRACT. In this article we try to approach the figure of San Juan de la Cruz, significant presence in the Spanish mystic, and reformer of Carmelite Order, through the miracle happened in the Carmelite convent of San José in Medina del Campo with one of his relics. Fact which led to a significant change in iconography, little known, however, resulted in numerous and outstanding artistic pieces (paintings, prints...) not only at local but also national and even international levels.

Key words: San Juan de la Cruz, Orden del Carmen, miracle, Vigil de Quiñones, Diego Valentín Díaz.

\section{SAN JUAN DE LA CRUZ. VIDA Y CONTACTO CON EL CARMELO}

Como ya es de sobra conocido, Juan de Yepes nace en Fontíveros (Ávila) hacia 1542, en el seno de una familia humilde. Tras la muerte de su padre, Gonzalo, su madre quedó prácticamente en la miseria con tres niños pequeños, siendo Juan el menor de ellos. Buscando un futuro para ella y sus hijos, decide trasladarse primero a Arévalo y posteriormente a la villa de Medina del Campo. Ciudad próspera gra- cias a las ferias ${ }^{1}$ que se celebraban anualmente en ella, y a las que acudían mercaderes de las más diversas partes de Europa:

"Primeramente si conocieron al dicho Fray Juan de la Cruz que en el siglo se llamó Juan de Yepes, y si saben que fue hijo de padres muy

-

${ }^{1}$ J. A. Álvarez VÁzQUez, Trabajos dineros y negocios. Teresa de Jesús y la economía del S. XVI (1562-1582), Madrid, 2000, pp. 239-279; C. ESPEJO, Las antiguas ferias de Medina del Campo: investigación histórica acerca de ellas, Valladolid, 2003; A. RoJO VEGA, Guía de mercaderes y mercaderías en las ferias de Medina del Campo: S.XVI, Valladolid, 2004. 
cristianos... en la villa de Medina del Campo donde eran naturales" ${ }^{2}$.

En esta villa comenzó Juan de Yepes a trabajar en los más variados oficios, entre los que cabría destacar, desde nuestro punto de vista, el de entallador o pintor, algo que le influiría a lo largo de toda su vida:

"... con muchos trabajos acordó pasarse a vivir a Medina del Campo donde para tener algún alivio procuró poner a oficio al padre Fray Juan de la Cruz y procurando algunos como carpintero, sastre, entallador y pintor a ninguno de ellos asentó ni pudo aprenderle aunque él deseaba aplicarse a ganar de comer..."

Sobre esta etapa nos gustaría hacer un inciso, pues Juan de Yepes en cierta manera no abandonó la práctica del arte a lo largo de toda su vida. Es famosa la imagen de Cristo dibujada por él mismo, o la síntesis gráfica que buscó de su doctrina mística en el dibujo de "Subida al Monte Carmelo" y que muchos novicios llevaban en sus breviarios ${ }^{4}$. Podríamos decir que lo ejercía como una afición complementaria a sus obligaciones dentro de la Orden:

"el tiempo que le sobraba de sus obligaciones y ocupaciones, que eran muchas lo gastaba como por recreación en labrar unos Cristos de madera que hacía"

Incluso durante el duro período de encarcelamiento en Toledo, debido a su condición de fraile descalzo, sabemos que labraba pequeñas imágenes de madera, una

\footnotetext{
${ }^{2}$ S. De SANTA Teresa, C.D., Obras de San Juan de la Cruz. Doctor de la Iglesia. Editadas y anotadas por el $P$. Silverio de Santa Teresa C.D., Tomo V, Procesos de beatificación y canonización. Biblioteca Mística Carmelitana, Burgos, "Monte Carmelo", 1931, pp. 1-11.

${ }^{3}$ Mss. 12738, B.N.E., Informaciones sobre la vida $y$ milagros de San Juan de la Cruz para su beatificación, fol. 611 .

${ }^{4}$ Ms. Vaticano 2864, Biblioteca Apostólica Vaticana, fols. 13-14, en VV.AA., Subida del Monte Carmelo, $2^{-}$ edición, Madrid, 1983.

${ }^{5}$ Mss. 13482, B.N.E., fol. 58, en E. OrOzCO DíAZ, Mística, plástica y barroco, Madrid, 1977, pp. 50-52.
}

de las cuales entregó como presente a su propio carcelero ${ }^{6}$ :

"Tengo por cierto era obra hecha por manos del Santo, porque en las horas de recreación, con una punta como de lanceta labraba curiosamente imagencitas"

Estudió en el Colegio de los Niños de la Doctrina de Medina, mientras que a su vez servía como ayudante en el Hospital de las Bubas, a cuyo cargo estaba Don Álvaro Fernández de Toledo, quien pronto dio cuenta de las virtudes de Juan:

"Si saben que el dicho padre Fray Juan de la Cruz desde niño se crió en temor de Dios y dio grandes muestras de virtud, con las cuales sirvió en un hospital de la dicha villa... allí a persuasión de Don Álvaro Fernández de Toledo, a cuyo cargo estaba dicho hospital, estudió Gramática..."7

“... poner en el Colegio de los Niños de la Doctrina de esta villa donde aprendió en pocos días a leer y escribir, desde a poco tiempo que estuvo en este colegio un caballero muy cristiano y siervo de Dios que se llamaba Alonso Álvarez de Toledo el cual se había recogido a un hospital a servir y curar los pobres le llevó consigo y le dio cuidado... le dio licencia para que fuese a oír gramática al colegio de la Compañía de Jesús donde fue su preceptor el padre Bonifacio..." ${ }^{8}$

Don Álvaro intentó que tras acabar sus estudios en 1563, Juan aceptase ordenarse sacerdote y tomase la capellanía de dicho Hospital. Algo que no aceptó, pues estaba decidido a entrar en religión:

"...trató Alonso Álvarez de Toledo que se ordenase a título de la capellanía del Hospital que le quería dar. Agradeció la oferta como era razón pero no dándole la humildad licencia para aceptar tan alta dignidad... consultaba entre sí que reli-

\footnotetext{
${ }^{6}$ Ibídem.

${ }^{7}$ S. De SANTA Teresa C.D., Obras..., op. cit., pp. 111

${ }^{8}$ Mss. 12738, B.N.E., Informaciones..., op. cit. fol. $611 r$.
} 
gión elegiría más acomodada a su llamamiento..."

Sobre el por qué elige la Orden del Carmen se apunta a varios motivos que expondremos de manera muy sucinta. Entre ellos, la llegada a Medina de los Carmelitas Calzados, quienes establecieron allí el desaparecido convento de Santa Ana, y que debido a su especial devoción a María, propia de la Orden, impresionarían al joven:

“...Eran recién entrados en aquella villa los Padres Carmelitas de la Observancia y habían fundado el convento de Santa Ana a que como madre de Nuestra Señora eligieron por abogada. Derramose luego por la villa que aquella religión era antiquísima y fundada debajo del patrocinio de la Virgen Santísima. La devoción de esta señora y la antigüedad de la Orden presto le ganaron la inclinación..."

"El se acogió a lo más seguro y, determinado a entrar en religión puso los ojos en la Orden del Carmen desta villa donde pidió el hábito"11

"Estando en casa del dicho Francisco de Yepes le oí decir que el dicho Juan, su hermano, se había ido del dicho Hospital General y recibido el hábito del Carmen en el Monasterio de Santa Ana de esta villa... Se salió del dicho Hospital donde estaba y se fue al convento de Santa Ana, de la Orden de Nuestra Señora del Carmen en esta dicha villa y tomó el hábito del paño, y allí le vi y hablé con él ${ }^{\prime 12}$

${ }^{9}$ F. De SANTA MARÍA, Reforma de los Descalzos de Nuestra Señora del Carmen de la antigua observancia hecha por Santa Teresa de Jesús en la antiquiísima religión fundada por el Profeta Elías. Al eminentísimo y reverendísimo señor cardenal D. Baltasar de Moscoso y Sandoval arzobispo de Toledo. Por el P. Fray Francisco de Santa María su general historiador natural de Granada. Tomo II. Madrid, 1655, Cap. II.

${ }^{10}$ Ibídem.

${ }^{11}$ Mss. 12738, B.NE., Informaciones..., op. cit., fol. 613.

12 Ms. Vaticano 2840, Biblioteca Apostólica Vaticana, Proceso informativo en Medina del Campo, fols. 60 y 62, en C. DE Jesús O.C.D., Vida y obras de San Juan de la Cruz, Sexta Edición, Madrid, 1972, pp. 13-21.
$\mathrm{Su}$ relación con la Virgen fue muy importante y marcó algunos de los momentos más destacados de su iconografía "...desde niño fue muy devoto de la Virgen Nuestra Señora y recibió de ella favores milagrosos..."13. Sería esta predilección por la madre de Jesús lo que le llevó a elegir el Carmelo. Así lo refieren algunos testigos interrogados en los procesos de Medina abiertos de cara a su beatificación, como Juan López de Osorio y Pedro Fernández Bustillo:

"Con la devoción tan grande que tenía de Nuestra Señora tomó el hábito de Carmelita de la observancia en el monasterio de Nuestra Señora del Carmen advocación de Santa Ana de esta villa donde le vi"14

“... el dicho padre por la devoción grande que tenía con Nuestra Señora, se entró en la religión del Carmen dedicada a Ella, en el convento de Santa Ana de la misma villa de Medina del Campo..." 15

También se apela a motivos más propios del mundo de la mística. Siendo aún un niño gozó de una revelación milagrosa por medio de la cual se le comunicó que su destino era pertenecer a una orden religiosa de gran antigüedad, que el autor que refiere este hecho identifica con la Orden del Carmen:

"Estaba un día el devoto mancebo orando con el fervor y devoción que solía, y rogaba con ansias al Señor fuese servido de encaminarle al estado de vida que más le hubiese de agradar... Oyó el Señor su oración y... consoló a su siervo respondiendo a sus deseos con este oráculo divino: 
"Servirme has (le dijo) en una religión cuya perfección antigua ayudarás a levantar"16

Otros testigos, como María de Jesús, religiosa en Lerma, dice haber oído a la Madre Ana de Jesús “...que está ahora en Flandes", que Juan de Yepes habría optado por una orden en decadencia:

"Siendo de muy poca edad, tuvo llamamiento para ser religioso, $y$ en elegir en cual religión lo sería dudaba, porque deseaba serlo en la que estuviese más relajada para hacer cuanto pudiese por reformarla... Y como en el pueblo donde él estaba se fundó en aquella sazón un convento del Carmen y con ocasión de no estar aún bien asentado debía ver algunos desconciertos, le pareció era aquello lo que él buscaba, y allí tomó el hábito" ${ }^{17}$

Con respecto a la fecha exacta de la toma del hábito y profesión, hay algunas dudas, según el Padre Alonso Asturicense quien conoció el original del "Libro de Profesiones" que hoy no se conserva, la de Juan de Yepes sería la sexta en número. Entraría en el convento hacia 1562-1563 y profesaría en la segunda mitad de 1564. Alonso de la Madre de Dios en su obra: "Vida y virtudes", nos aportó la fórmula completa: "Ego, frater Johannes a Sancto Matía, filius etc...promitto obedientiam, castitatem et paupertatem. Deo et Beatae Mariae de Monte Carmelo et reverendo Patri Fratri Joanni Baptistae Rubeo de Ravenna, Priori Generali Ordinis Carmelitarum, usque ad mortem. Testibus etc. Frater Johannes de Sancto Mathia". Puesto que fue bajo el generalato de Rubeo no pudo ser antes de 1563 (fue elegido en Roma el 21 de mayo de ese año) ${ }^{18}$.Coincide Fray José de Santa Teresa, cronista de la Orden:

${ }^{16}$ J. De SAN JOSE, Historia, 1.1 c.4, pp. 27-28. 911.

${ }^{17}$ Mss. 12738, B.N.E., Informaciones..., op. cit., fol.

18 Ms. 19404, B.N.E., fol. 181, en C. DE JESÚs O.C.D., Vida..., op. cit., p.47. “...recibióle el año de 1563 y a los 21 de su edad. Quedó tan gozoso de esta buena suerte que pareciéndole haber caído sobre él la de Matías (quizá porque en su día recibió el hábito) dejando el apellido de Yepes añadió sobre el nombre de Juan, el de este sagrado apóstol llamándose Fray Juan de San Matía. Aunque en la descalcez eligió el de la Cruz... hízola (profesión) al año siguiente de 1564 y poco después lo pasaron al Colegio de San Andrés (hoy de Santa Teresa)..."19

Sin embargo, en una de las Informaciones de Medina, el Padre Maestro Fray Antonio de Sagrameña habla del mencionado "Libro de Profesiones", que él conoció y que "adecentó" bajo su mandato, mandándolo encuadernar en cuero negro dorado y decorando su portada con una imagen del Santo: utilizó una de sus iconografías más habituales ${ }^{20}$, como escritor, portando una cruz, acompañado de un ángel y recibiendo la inspiración del Espíritu Santo en forma de rayo luminoso. En dicho libro aparecería como fecha de la profesión de Juan de Yepes el año de 1560, lo que adelantaría su contacto con el Carmelo. Además Fray Antonio reservó una zona en el convento destinada a custodiar el documento, que presidiría una escultura de San Juan, realizada en bulto redondo:

"El Padre Maestro Fray Antonio de Sagrameña prior que fue del convento de Santa Ana de Carmelitas Calzados de Medina del Campo dice, que en el libro antiguo de las profesiones del dicho monasterio está la de nuestro venerable padre y que según ella tomaría el hábito el año de

-

${ }^{19}$ J. DE SANTA TERESA, Resunta de la vida del Bienaventurado Padre San Juan de la Cruz doctor místico. Primer carmelita descalzo y fiel coadjutor de Nuestra Madre Santa Teresa en la fundación de su reforma. Beatificado por nuestro Santísimo Padre Clemente X a 6 de octubre de 1674. Ofrécela a N.M.R. P. Fray Diego de la Concepción General dignísimo de los descalzos de Nuestra Señora del Carmen de la primitiva observancia. Su autor el Padre Fray José de Santa Teresa, coronista general de dicha reforma. Madrid, 1675 , fol. $12 \mathrm{v}^{\mathrm{o}}$.

${ }^{20}$ F. MORENO CUADRO, San Juan de la Cruz y el grabado carmelitano del Teresianum de Roma, Madrid, 1991, pp. 10-34. 
1560 y que siendo prior este testigo del dicho monasterio tuvo un impulso interior de poner con decencia aquel libro por estar allí aquella profesión y así lo hizo encuadernar en cuero negro dorado todo con las armas de la orden y por principio la imagen de nuestro venerable padre como suelen pintarla con una cruz en la mano y un querubín al lado derecho que envía un rayo de luz al oído y dice también que en el capitulo del convento hizo poner una imagen de cuerpo entero de nuestro venerable padre y a un lado de esta imagen un archivo en que estuviese el libro de las profesiones en veneración de estar allí la suya." ${ }^{21}$

Los testigos fueron Fray Ángel de Salazar, provincial (quien le profesó), Fray Ildefonso Ruiz rector de la casa y Alonso Álvarez de Toledo devoto y patrón. Toma ese nombre por coincidir con el santo del día ${ }^{22}$. Tras esto se traslada al Colegio del Carmen de Salamanca (actualmente de Santa Teresa), donde acabó sus estudios. Pasados cuatro años regresa a Medina:

"Después de haber acabado sus estudios en el dicho colegio de Salamanca el dicho siervo de Dios Fr. Juan de la Cruz volvió al dicho convento de Santa Ana en esta dicha villa por pasante de sus estudios" 23

Una vez allí, Fray Juan de Santo Matía expresó a sus más allegados el deseo de emprender una vida de mayor austeridad y aislamiento entrando cartujo: "Si saben que en acabando sus estudios volvió a Medina del Campo con mayores deseos de la vida solitaria... por lo cual trataba de pasarse a la Cartuja..." 24 Lo que finalmente no llegó a hacer, puesto que es en este momento cuando Teresa de Jesús llega a la villa para fundar su convento de Carmelitas Descalzas, y tras conocerle

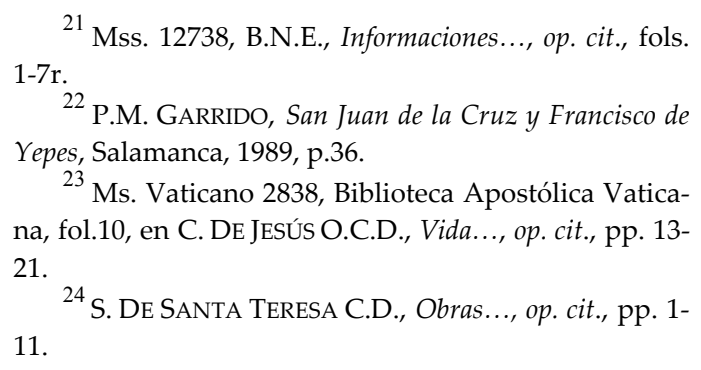

${ }^{23}$ Ms. Vaticano 2838, Biblioteca Apostólica Vaticana, fol.10, en C. DE Jesús O.C.D., Vida..., op. cit., pp. 1321. 11.

le persuade de que sea su "mano derecha" en la reforma que está por hacer:

“...Y en este tiempo llegó a aquella villa la Bienaventurada Madre Teresa de Jesús a fundar el convento de sus monjas... le persuadió a que procurase levantar una reformación que guardase en su rigor la regla primitiva de frailes, como la Santa la iba levantando de monjas..."25

"Mi hijo tenga paciencia y no se me vaya a la cartuja que ahora tratamos de hacer una reformación de descalzos de nuestra misma orden y se yo que se consolará con el aparejo que en ella tendrá para cumplir todos sus deseos de recogimiento y retiro de las cosas de acá y de oración y penitencia..." 26

Acompañó a la Santa a su fundación de Valladolid como capellán de las religiosas, y fue en ese convento donde recibió el hábito de Descalzo. Desde este momento cambió su nombre por Fray Juan de la Cruz. De aquí partirá a Duruelo, primera casa de Carmelitas Descalzos:

"... Se partió a Valladolid a fundar el $4^{\underline{0}}$ convento de monjas llevando en su compañía al Santo Fray Juan, asi para que le asistiese en aquella fundación como para instruirle la Santa fundadora en las obligaciones de la descalcez... cosió la santa ayudada de sus hijas los hábitos..." 27

\section{RELIQUIA Y MILAGROS. SU TRAS- CENDENCIA ARTÍSTICA:}

Según se relata en "Informaciones sobre la vida y milagros de San Juan de la Cruz" fue en enero de 1594, poco después de morir el santo, cuando en un relicario que contenía un pedazo de su carne, custodiado en el medinense convento de San José, comenzaron a aparecer diversas figuras. El hecho llegó a oídos del obispo de Valladolid: Don Juan Vigil de Quiñones, quien hizo las averiguaciones necesarias

\footnotetext{
${ }^{25}$ Ibídem.

${ }^{26}$ Mss. 12738, B.N.E., Informaciones..., op. cit., fols. $1-7 \mathrm{r}$.

${ }^{27}$ J. De SANTA TERESA, Resunta..., op. cit., fol. 19r.
} 
para comprobar la veracidad de lo acontecido:

"...En el año de 1594 día de la Epifanía dos años y 23 días después de la muerte del bienaventurado santo padre Fray Juan de la Cruz en Medina del Campo en un pequeño pedazo de carne del mismo santo, tenido allí en mucha veneración en un relicario comenzó nuestro señor a hacer diversas apariciones, sobre el cual milagro Don Vigil de Quiñones obispo de Valladolid hizo largas y rigurosas informaciones..." 28

Tras recabar la información de numerosos testigos, y someter la reliquia al examen de pintores, plateros, médicos... ${ }^{29} \mathrm{y}$ tras comprobar que no había artificio alguno, declaró el hecho realmente milagroso el año de 1615: "declaró ser milagro hecho en conformidad de la santidad del Santo Padre Fray Juan de la Cruz y así calificó el dicho milagro el año de $1615^{\prime \prime} .{ }^{30}$ Como hemos señalado, en dicha carne los testigos decían ver algunas imágenes, en las relaciones presentadas por el obispo, se detallan cuales son. Podríamos dividirlas en tres apartados:

a. Imágenes de Cristo: Crucificado aún vivo; Jesús muerto en la cruz y atravesado por una lanza: Cristo con la cabeza cubierta por una nube; Jesús atado a la columna; Cristo Salvador:

"Aparecese en la dicha carne Cristo crucificado como estaba antes de que expirase.

Aparece Cristo crucificado cubierto el rostro y el pecho con una nube.

Veese Cristo desnudo atado a una columna.

Veese un salvador hermoso y resplandeciente.

28 Mss. 12738, B.N.E., Informaciones..., op. cit., fol.695r.

${ }^{29}$ F. COLLAR DE CÁCERES, «En torno a la iconografía de San Juan de la Cruz. A propósito de su capillamausoleo», Boletín Camón Aznar, Madrid, 1983, pp. 1934. $695 \mathrm{r}$.
Veese Cristo crucificado muerto y atravesado con una lanza..." ${ }^{31}$

b. La Virgen con San Juan de la Cruz: en una de ellas aparecería María acompañada del Niño Jesús, quien pone sus manos sobre la cabeza del Santo; la Virgen coloca sus manos sobre el pecho de San Juan:

"Aparece la Virgen Nuestra Señora vestida del hábito de Carmelita con el Niño Jesús en los brazos el cual descolgándose de ellos pone la mano sobre la cabeza del Santo Padre Fray Juan como acariciándolo.

Aparece la misma Madre de Dios sin Nino poniendo las manos como en el corazón al Santo Padre Fray Juan y él se muestra muy humilde y como agradecido a la Virgen por tal favor ${ }^{\prime \prime 32}$

c. Otras imágenes: El Espíritu Santo en forma de paloma; el Santísimo Sacramento en una custodia; Un serafín; San José abrazando al San Juan de la Cruz, escena en la que aparece el hermano del santo, el venerable Francisco de Yepes: una custodia.

“... Aparece el Santísimo sacramento en

Aparece el Espíritu Santo en figura de paloma en un resplandor.

Aparece un serafin de extremada hermosura.

Veese a San José como apadrinando al Santo en estas apariciones también se ve el venerable Francisco de Yepes hermano del santo.",33

Dentro de los testimonios tomados a algunos artistas, destaca el del pintor medinense Pedro de Soria, quien tras ver esta reliquia afirmó haber visto en ella las imágenes mencionadas, que después pintó, de manera que así quedó fijada su iconografía. No obstante el obispo de Valladolid decidió que fuera Diego Valentín Díaz (que en los

\footnotetext{
${ }^{31}$ Ibídem.

${ }^{32}$ Mss. 12738, B.N.E., Informaciones..., op. cit., fol. $695 r$.

${ }^{33}$ Ibídem.
} 
textos aparece como Diego Díez o Díaz) uno de los más importantes pintores del Valladolid del XVII, quien realizase en pintura sobre papiro tres óvalos de pequeño tamaño $(75 \times 136 \mathrm{~mm})$ pegados a un soporte rectangular, y que se adjuntarían en el escrito que confirmaba el milagro:

"Nos Don Juan Vigil de Quiñones por la Gracia de Dios y de la Santa Sede Apostólica obispo de Valladolid y del Consejo del Rey Nuestro Señor aunque por el proceso hecho en contradictorio juicio por nuestra comisión especial en la villa de Medina del Campo de suso referido sobre la causa de la reliquia de la carne del Venerable Padre Fray Juan de la Cruz de buena memoria y de las maravillosas apariciones della obradas de Dios Nuestro Señor por particular milagro y obra sobrenatural de la diestra de él al dicho declaradas por tales por nos y por la nuestra sentencia dada en la dicha (---) a 19 días del presente mes y año por ante el infraescripto notario de esta dicha causa y por las deposiciones de los testigos en el dicho proceso examinado, mayores de toda excepción consta claramente la susodicha y modo de las apariciones y milagros de la dicha reliquia y carne, con todo ello nos que deseamos que lo por nos hecho y sentenciado sobre esta dicha causa en el hecho y en la verdad tenga debido efecto y de todas maneras reconocido, sea manifestado a todos los fieles para mayor gloria de Dios de nuestra deliberada voluntad y madura consideración usando de toda la facultad y poder que en esta parte tenemos y por la cual vía y forma nos compete de mío oficio y autoridad meramente, decimos que el día del milagro y maravillosas apariciones se pinta en este pergamino en la forma y manera que los testigos del dicho proceso y causa declaran y deponen aparecerse en la dicha reliquia y carne del dicho venerable Padre Fray Juan de la Cruz y de nuestro orden y mandamiento pintó Diego Díez pintor de los mejores de esta dicha ciudad las dichas apariciones y milagros sacándolas por la relación que le fue hecha de las dichas deposiciones $y$ de tres tarjetas originales en las cuales la primera vez se retrató y pintó el dicho milagro y dichas maravillosas apariciones por Pedro de Soria pintor de la dicha villa de Medina del Campo que fue uno de los testigos presentados en el otro proceso de la dicha causa, las cuales tarjetas llegaron a mis manos para que por vista de ojos se vean las dichas apariciones las mandamos copiar y sacar de pintura en la manera que aquí van puestas las cuales pinturas aprobamos por fiel y verdaderamente copiada en conformidad de lo que deponen los dichos testigos y por nos es y ha sido declarado en la dicha nuestra sentencia y damos licencia para que de ellas se pueda usar para el fin que al presente se presente y las mandamos poner en este dicho proceso... en Valladolid a 24 días de julio de 1615 años, el obispo de Valladolid." ${ }^{34}$

En esos tres óvalos aparecen representadas tres escenas de las que los testigos dijeron ver en la reliquia de la carne del santo:

- San Juan de la Cruz abrazado por María. Detrás la imagen de Cristo crucificado con su rostro oculto por las nubes, sobre las cuales aparece una custodia con el Santísimo Sacramento.

- San Juan de la Cruz orando ante el Crucificado que de nuevo oculta su cara entre las nubes. Se incluye también el Espíritu Santo como una paloma.

- La Virgen María con el Niño Jesús, quien toca la cabeza del Santo. Se ha interpretado como un símbolo de pureza. Detrás de ellos Cristo en la Cruz, cuya presencia fue explicada ${ }^{35}$ por la religiosa carmelita Ana de San Bartolomé como muestra de la mortificación practicada por San Juan. Asimismo aparece el Espíritu Santo, de nuevo en forma de paloma.

Por tanto como hemos visto este hecho derivó en una nueva iconografía asociada a San Juan de la Cruz, cuya primigenia representación fue hecha por uno de los más importantes artistas de Valladolid en ese momento, Diego Valentín Díaz. No obstante su trascendencia no quedó circunscrita a un ámbito local, pues de este tema se hicieron numerosas reproducciones

\footnotetext{
${ }^{34}$ Mss. 12738, B.N.E., Informaciones..., op. cit., fols. 1387-1388; 1240-1241.

${ }^{35}$ Mss. 8568, B.N.E., Informaciones de Medina, fol. 173.
} 
de mano de algunos de los más destacados grabadores del momento ${ }^{36}$ como: Cornelis Boel, presente en España en 1616, Wierix, Van Mallery o J. Galle.

De hecho, y por ser uno de los documentos que más información nos han aportado, querríamos hacer referencia al grabado que se utilizó en la portada de "Informaciones sobre la vida y milagros de San Juan de la Cruz". Podemos ver al santo en oración, arrodillado ante la cruz de la que pende una filacteria: "MIHI AVTEM ABSIT GLORIARI NISI IN CRVCE DOMINI NOSTRI IESVXPI". Junto a él una mesa con escritos: "Llama de amor viva", sus "No che Oscura" y "Subida al Monte Carmelo", junto con el tintero y la pluma, atributos

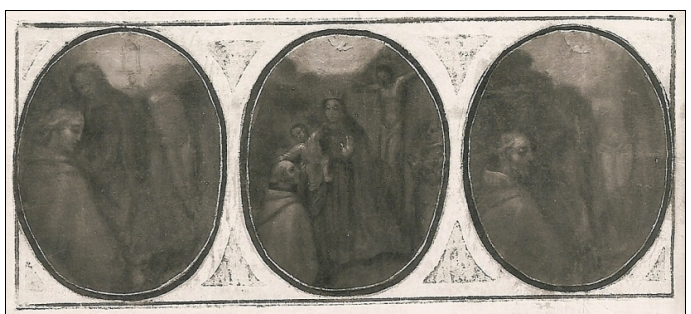

- Lám. 1. Miniaturas pintadas por Diego Valentín Díaz relatando el milagro. Mss. 12738, fols.1240-1241. iconográficos que lo presentan como el gran literato que fue. Ambientado en una gran arquitectura interior, de la que sólo podemos ver las columnas en cuya basa se sitúan los escudos del Carmelo Descalzo, el grabado se completa con los tres óvalos mencionados con anterioridad y que relatan el milagro vivido en Medina con la reliquia de la carne del santo. Al pie del grabado se añade una inscripción que aporta datos de la vida de San Juan: fecha de muerte, lugar de enterramiento... y cómo fue el mencionado Don Juan Vigil de Quiñones, obispo de Valladolid, quien el 24 de julio de 1615 aceptó la veracidad de estos hechos considerándolos milagrosos.

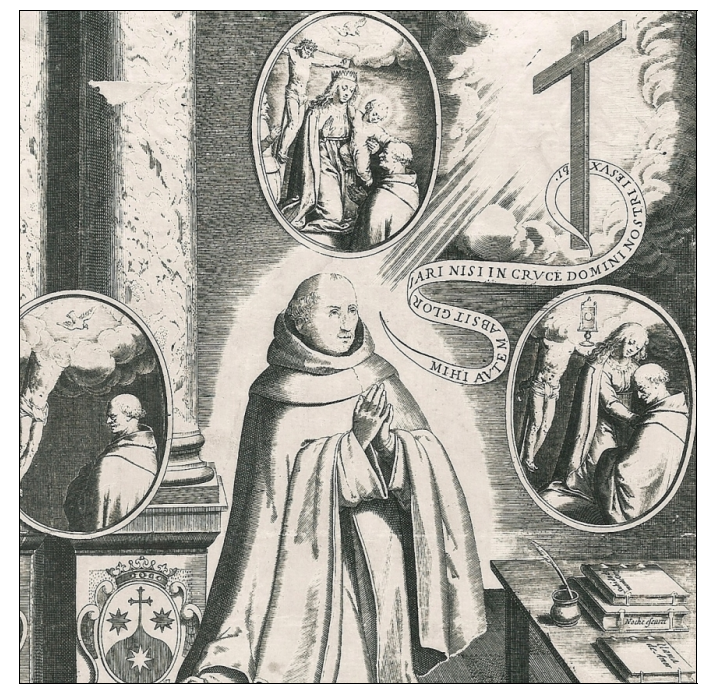

- Lám. 2. Grabado portada de «Informaciones sobre la vida y milagros de San Juan de la Cruz», Mss. 12738. B.N.

\footnotetext{
${ }^{36}$ F. COLLAR DE CÁCERES, «En torno a la iconografía...», op. cit., pp. 19-34.
} 